\title{
Sağlık Evi Ebelerinin Çalışma Koşulları ve Memnuniyet Durumlarının Araştıııması
}

\author{
Ilnvestigation of Working Conditions and Satisfaction Status of \\ Health House Midwives
}

\section{Muhsin Akbabal, Dilek Öztaş2, Burak Kurt1, Gülseher Sanaç3 \\ ' Çukurova Üniversitesi Tıp Fakültesi Halk Sağlığı Anabilim Dalı, Adana 2 Yıldırım Beyazı Üniversitesi Tıp Fakültesi Halk Sağlığı Anabilim Dalı, Ankara ${ }^{3}$ T.C. Sağılık Bakanlığı Sağlık Bilgi Sistemleri Genel Müdürlüğü, Ankara}

\author{
Yazışma Adresi / Correspondence: \\ Burak Kurt
}

Çukurova Üniversitesi Halk Sağı̆ı̆ı Anabilim Dalı Sarıçam/ADANA

T: +90 3223386060 / 3108 E-mail: kurtburak@msn.com

Geliş Tarihi / Received : 05.04.2018 Kabul Tarihi / Accepted : 18.05.2018

\footnotetext{
Öz

Amaç Bu çalışmanın amacı, sağık evlerinde çalışan ebelerin çalışma koşullarııı ve memnuniyetlerinin değerlendirilmesidir. Sakarya Tip Dergisi, 2018, 8(2):344-351 )

Gereç ve Bu çalıșma, kesitsel tipte tanımlayıcı bir araștırmadır. Gerekli izinler alındıktan sonra, Türkiye Halk Sağlığı Kurumu tarafından 11 Mayıs-12 Yöntem Haziran 2017 tarihleri arasında sağık evlerinde çalışan tüm ebelere online ortamda anket gönderilmiştir. Toplam 3510 ebeden 2676 'si katılım sağlamıştır $(\% 76,2)$. Verilerin istatistiksel değerlendirilmesinde SPSS programı kullanılmıştır.

Bulgular Yaş ortalaması $32.4 \pm 7.8$ olup, ortalama $5.5 \pm 5.1$ yıldır şu anki sağlık evinde çalışmaktaydılar. \% 87 ’si mesleğini severek yaptığını belirtirken sadece \%34'ü yaptığ ișe toplumun, yeterince saygı duyduğunu ve değer verdiğini düşünüyordu. Özlük haklarının yeterli olduğunu düşünen katılımcı oranı \%20 dolaylarındaydı. Sağık evi binasının fiziksel durumunu yeterli veya çok yeterli görenlerin oranı \%22,1 idi.

Sonuç Sağlık evi ebelerinin mesleki memnuniyeti yüksek olmakla birlikte, özlük hakları konusunda bazı talepleri mevcuttur. Ayrıca, sağlık evlerinin fiziksel durumları konusunda da yetersizlikler mevcuttur.

Anahtar Sağık evi; Ebe; Çalışma Koşulları; Memnuniyet

Kelimeler
}

\footnotetext{
Abstract

Purpose The aim of this study is to evaluate the working conditions and job satisfaction of health workers working in health houses. ( Sakarya Med J, 2018, 8(2):344-351 ).

Materials and This research is a cross-sectional descriptive study. After receiving the necessary permissions, questionnaires in online environment were Methods sent by Public Health Agency of Turkey from 11 May to 12 June 2017 to all midwives working in health houses. A total of 2676 midwives, from 3510 contributed (76.2\%). SPSS program was used in the statistical evaluation of the data.

Results The mean age was $32.4 \pm 7.8$ years and they were working in the present health house for a mean of $5.5 \pm 5.1$ years. $87 \%$ of the respondents said they liked their job, although only $34 \%$ thought it was enough to respect and value the work. Participants who thought that their personal rights were sufficient was around $20 \%$. The proportion of those who saw the physical condition of the health home building as adequate or sufficient was $22.1 \%$.

Conclusion Health house midwives have high occupational satisfaction and but have some demands for personal rights. In addition, there are shortcomings in the physical condition of health care houses.

KeyWords Health house; Midwife; Working Conditions; Satisfaction
} 
Sakarya TIp Dergisi 2018;8(2):344-351

\section{Giriş}

Ülkemizde sağlık evleri ilk kez 1961 yılında kabul edilen 224 Sayılı Sağlık Hizmetlerinin Sosyalleştirilmesi Hakkında Kanun çerçevesinde sağlık ocaklarına bağlı olarak kurulmuşlardı. ${ }^{1}$ Sağlık hizmetlerinin en uç noktadaki sağlık birimleriydi ve öncelikli işi ana ve çocuk sağlığı hizmetlerini yürütmekti. Değişen koşullar ve 663 Sayılı KHK uyarınca şimdiki statüsüne getirildi. “Türkiye Halk Sağı̆ğı Kurumu Taşra Teşkilatları Hizmet Birimlerinin Görevleri, Çalışma Usul ve Esasları ile Kadro Standartları Hakkında Yönergesinin" 8. maddesinin, 7. fıkrasında sağlık evlerinin kuruluşu; "Türkiye İstatistik Kurumu verilerine göre toplam nüfusu 500'ün üzerinde olan belde, köy ve mezralarda Müdürlüğün teklifi ve Kurumun onayı ile sağık evleri açılabilir. Bir sağlık evine birden fazla belde, köy ve mezra bağlanabilir. Sağlık evleri idari yönden toplum sağlğı merkezine, hizmet yönünden ise aile hekimlerine bağlı birimlerdir. Sağlık evlerinin görev ve yetkileri Kurumca belirlenir." olarak belirtilmiştir. ${ }^{2}$ Sağlık evlerinde personel olarak yalnızca ebe ya da ebe hemşire görevlidir; başka personel bulunmaz. Sağlık evlerinde yerine getirilen başlıca görevler; anne, çocuk sağlığı hizmetleri, sıtma eradikasyon hizmetleri, hasta takibi ve eğitimi, aile planlaması hizmetleri, çevrenin düzenlenmesi ve korunması, sağık eğitimi hizmetleri, ilk yardım ve acil tedavi hizmetleri, sosyal yardım hizmetleri verilmektedir. $^{3}$

Doğrudan insana hizmet eden ve hizmetin kalitesinde insan etmeninin çok önemli bir yere sahip olduğu sağık alanında, çalışanların özellikle de ebe-hemşirelerin mesleki sorunlarının düzeltilmesinin, çalışma koşullarının iyileştirilmesinin ve iş doyumunun arttırımasının, bireysel olduğu kadar kurumsal, toplumsal ve sağlık politikasıyla da ilgili önemli boyutları olan tükenmişliğin gelişmesini önlemek açısından önem taşımaktadır. ${ }^{4,5}$

\section{Gereç ve Yöntemler}

Amaç

Bu çalışma, kesitsel tipte tanımlayıcı bir araştırmadır. Araştırmada, sağlık evlerinde çalışan ebelerin çalışma koşullarının ve memnuniyetlerinin değerlendirilmesi ve çıkacak olan sonuçlara göre gereken planlama ve uygulama çalışmalarının yapılması ve değerlendirilmelerin gerçekleştirilebilmesi için; sağık evi personel memnuniyet durum analizi anketi ve gerekli çalışmalar yapılmıştır.

\section{Araştırmanın Örneklemi ve Veri Toplama Aracı}

Türkiye Halk Sağlğı Kurumu (THSK) Toplum Sağlığı Hizmetleri Daire Başkanlığı tarafından hazırlanmış olan Sağlık Evi Ebeleri Anketi, THSK İstatistik ve Bilgi İşlem Daire Başkanlığı tarafından 11 Mayıs-12 Haziran 2017 tarihleri arasında Lime Survey yazılımı üzerinden online olarak sağık evlerinde çalışan tüm ebelere gönderilmiştir. Toplam 3510 ebeden 2676'si katılım sağlamıştır. $(\% 76,2)$

\section{Verilerin Değerlendirilmesi}

Anket sonucunda elde edilen verilerin istatistiksel değerlendirilmesinde SPSS (Statistical Package for Social Science) 23.0 programı kullanılmıştır. Veriler, yüzde, ortalama, standart sapma kullanılarak değerlendirilmiştir.

\section{Araştırmanın Etik Yönü}

Araştırmaya başlamadan önce Türkiye Halk Sağlığı Kurumu Başkanlığı'ndan ve Ankara Yıldırım Beyazıt Üniversitesi Sosyal ve Beşeri Bilimler Etik Kurulu'ndan izin alınmıştır. Katılımcılardan ise ankete başlamadan önce araştırmanın amacı ve önemi hakkında bilgi verilip online izin alınmıştır. 


\section{Araştırmanın Sınırlılıkları}

Araştırma, 11 Mayıs-12 Haziran 2017 tarihleri arasında ülkemiz sınırlarında yer alan Sağlık evlerinde çalışan ebelere uygulanmıştır.

\section{Bulgular}

Ankete katılan ebelerin \%69.5’i evli, \%27.3 ü ise bekardır. Ebelerin \%32.7'si lise/meslek lisesi mezunu, \%17.2'si 2 yıllık yüksekokul/önlisans mezunu, \%48.6'sı ise 4 yıllık yüksekokul/lisans mezunudur. Çalışmaya katılan 2676 ebenin sadece 40’ı (\%1.5) yüksek lisans/doktora mezunudur. (Tablo 1)

\section{Tablo 1. Katılımcıların Demografik Özellikleri-1}

\begin{tabular}{|l|l|l|l|}
\hline & & Sıklık & Yüzde \\
\hline \multirow{4}{*}{ Medeni Durum } & Evli & 1861 & 69.5 \\
\cline { 2 - 4 } & Bekar & 730 & 27.3 \\
\cline { 2 - 4 } & Boşanmış & 85 & 3.2 \\
\hline \multirow{5}{*}{ Eğitim Durumu } & Lise/Meslek Lisesi & 874 & 32.7 \\
\cline { 2 - 4 } & 2 Yıllık Yüksekokul/Önlisans & 461 & 17.2 \\
\cline { 2 - 4 } & 4 Yıllık Yüksekokul/Lisans & 1301 & 48.6 \\
\cline { 2 - 4 } & Yüksek Lisans/Doktora(Diğer) & 40 & 1.5 \\
\hline
\end{tabular}

Sağlık evinde çalışan ebelerin ortalama gelirleri yaklaşık 2877 TL'dir. Yaş ortalaması 32'dir. Katılımcılar ortalama 9.5 yıldır çalışıyorken, şu anki yerde ortalama çalışma süreleri yaklaşık 5 yıldır. Bu bilgiler Tablo 2'de mevcuttur.

\begin{tabular}{|l|c|c|c|c|}
\hline \multicolumn{1}{|l|}{ Tablo 2. Katılımcıların Demografik Özellikleri-2 } \\
\hline & Ortalama & Minimum & Maksimum & Standart Sapma \\
\hline Gelir & 2877.32 TL & 1250TL & $7500 T L$ & 426.042 \\
\hline Yaş & 32.42 & 18 & 67 & 7.790 \\
\hline Çalışma yılı & 9.52 & 1 & 43 & 7.737 \\
\hline Şu an ki işyerinde çalışma yılı & 4.97 & 1 & 38 & 5.047 \\
\hline
\end{tabular}

Ankete katılan sağlık evi ebelerinin yarısının toplam aylık geliri 2500 ile 3000TL arasındadır. Maksimum gelirin 7500TL olduğu gözlemlenmiş olup, bu adaletsizliğin, ilgili anket sorusunun yanlış anlaşılmasından kaynaklı olduğu düşünülmelidir.(sorudan "haneye giren toplam gelir" anlaşılmış olabilir.) Katılımcıların \%21.5'inin 2500TL ve daha az maaş aldığı, \%28.5'inin ise 3000TL'den daha fazla maaş aldığı gözlemlenmiştir.

Sağlık evinde çalışan ebelerin \%37'si 1-5 yıl arası,\%30'u 6-10 yıl arası olmak üzere yaklaşık \%81'i 15 yıl ve daha az süredir çalışmaktadır.

Şu anki işyerinde 1 ile 5 yıl arasında bir sürede çalışan ebelerin oranı \%67'dir. Sağlık evinde çalışan ebelerin \%2.7'si şu an ki iş yerinde 21 yıl ve daha fazla süredir çalışmaktadır. (Tablo 3)

Fiziksel Durum: Tablo 4'de sıklık ve yüzde değerleri yer almaktadır. Buna göre, araştırmaya katılan ebelerin çalıştığı sağlık evlerinin \%80.7’sinin mülkiyeti Halk Sağlığı Müdürlüklerine aittir. Ebelerin \%45.6'sı çalıştıkları binaların fiziksel durumunun yetersiz ve çok yetersiz olduğunu düşünmektedir.
Sakarya Tıp Dergisi

2018;8(2):344-351

\section{KURT ve Ark.}


Binalarının fiziksel durumunun çok yeterli olduğunu ifade edenler ise katılım sağlayan ebelerin \%1.2'sini oluşturmaktadır. Sağlık evlerinin \%90 ında çalışma ve poliklinik odası var iken, gebe izlem ve aile Planlaması odası yalnızca \%49.2'sinde mevcuttur. Sağık evlerinin sadece \%59'unda, çalışma ve poliklinik odalarında gerekli demirbaş ve malzeme vardır. Özürlü ve Yaşlı Hastaların Giriş ve çıkışlarını Mümkün Kılan Kolaylaştıııı Tedbirler, maalesef sadece 100 sağlık evinden, 25 tanesinde bulunmaktadır. Katılım sağlayan sağık evlerinin sadece $\% 56.8$ 'i gezici hizmet verdiğini beyan etmiştir. (Tablo 4)

\begin{tabular}{|c|c|c|c|}
\hline & & Sıklık & Yüzde \\
\hline \multirow{5}{*}{ Gelir } & 1250 TL -2000TL & 69 & 2.6 \\
\hline & $2001 \mathrm{TL}-2500 \mathrm{TL}$ & 505 & 18.9 \\
\hline & $2501 \mathrm{TL}-3000 \mathrm{TL}$ & 1339 & 50.0 \\
\hline & 3001 TL -3500 TL & 717 & 26.8 \\
\hline & $3500 \mathrm{TL}+$ & 46 & 1.7 \\
\hline \multirow{6}{*}{ Çalışma Yılı } & $1-5 \mathrm{yll}$ & 992 & 37.1 \\
\hline & 6-10 yıl & 802 & 30.0 \\
\hline & $11-15$ yll & 369 & 13.8 \\
\hline & $16-20 \mathrm{yll}$ & 194 & 7.2 \\
\hline & 21-25 yıl & 169 & 6.3 \\
\hline & $26+y \mathrm{yl}$ & 150 & 5.6 \\
\hline \multirow{5}{*}{$\begin{array}{l}\text { Şu anki İş Yerinde Çalışma } \\
\text { Yilınız }\end{array}$} & 1-5 yıl & 1794 & 67.0 \\
\hline & 6-10 yıl & 609 & 22.8 \\
\hline & $11-15 \mathrm{yll}$ & 148 & 5.5 \\
\hline & $16-20 \mathrm{yll}$ & 53 & 2.0 \\
\hline & $21+y \mathrm{ll}$ & 72 & 2.7 \\
\hline
\end{tabular}

Tablo 4. Sağlık Evinin Fiziksel Özellikleri-1

\begin{tabular}{|c|c|c|c|}
\hline & & Sıklık & Yüzde \\
\hline \multirow{3}{*}{ Bina Mülkiyeti } & Halk Sağlığı Müdürlüğü & 2160 & 80.7 \\
\hline & Diğer Kamu & 372 & 13.9 \\
\hline & Özel & 144 & 5.4 \\
\hline \multirow{5}{*}{ Binanın Fiziksel Durumu } & Çok Yetersiz & 511 & 19.1 \\
\hline & Yetersiz & 709 & 26.5 \\
\hline & Orta & 863 & 32.2 \\
\hline & Yeterli & 560 & 20.9 \\
\hline & Çok Yeterli & 33 & 1.2 \\
\hline \multirow{2}{*}{ Çalışma ve Poliklinik Odası var mı? } & Evet & 2411 & 90.1 \\
\hline & Hayıг & 265 & 9.9 \\
\hline \multirow{2}{*}{ Gebe izlem ve Aile Planlamasi Odasi var mı? } & Evet & 1316 & 49.2 \\
\hline & Hayıг & 1360 & 50.8 \\
\hline \multirow{2}{*}{$\begin{array}{l}\text { Çalışma ve Poliklinik Odasında Gerekli Demirbaş ve } \\
\text { Malzeme var mı? }\end{array}$} & Evet & 1584 & 59.2 \\
\hline & Hayıг & 1092 & 40.8 \\
\hline \multirow{2}{*}{$\begin{array}{l}\text { Özürlü ve Yaşı Hastaların Giriş ve çııışlarını Mümkün } \\
\text { Kılan Kolaylaştıııı Tedbirler Alınmış mı? }\end{array}$} & Evet & 672 & 25.1 \\
\hline & Hayıг & 2004 & 74.9 \\
\hline \multirow{2}{*}{ Gezici Hizmet/Mobil Hizmet Veriyor Musunuz? } & Evet & 1520 & 56.8 \\
\hline & Hayıг & 1156 & 43.2 \\
\hline
\end{tabular}


Tablo 5'e bakılırsa; Sağık evlerinin \%80'inde lojman varken, araştırmaya katılan ebelerin yalnızca \%37.5'i lojmanda ikamet etmektedir. Ayrıca ebelerin \%42.8'i sağılık evinin bulunduğu yerde oturduğunu bildirmiştir. Sağılk evi ile aynı binada oturan ebelerin oranı \%31 olup katılımcıların neredeyse yarısı işyerine $15 \mathrm{dk}$ 'dan daha az bir sürede gidip geldiğini belirtmişlerdir.

\begin{tabular}{|c|c|c|c|}
\hline & & Sıklık & Yüzde \\
\hline \multirow{2}{*}{ Lojman var mı? } & Evet & 2139 & 79.9 \\
\hline & Hayıг & 537 & 20.1 \\
\hline \multirow{3}{*}{ Oturduğunuz yer } & Lojman & 1004 & 37.5 \\
\hline & Kendi evim & 980 & 36.6 \\
\hline & Kira & 692 & 25.9 \\
\hline \multirow{2}{*}{ Ehliyetiniz var mı? } & Evet & 2044 & 76.4 \\
\hline & Hayıг & 632 & 23.6 \\
\hline \multirow{2}{*}{ Ehliyetiniz varsa, araç kullanabiliyor musunuz? } & Evet & 1480 & 72.4 \\
\hline & Hayıг & 564 & 27.6 \\
\hline \multirow{2}{*}{ Sağlık evinin bulunduğu yerde mi oturuyorsunuz? } & Evet & 1144 & 42.8 \\
\hline & Hayıг & 1532 & 57.2 \\
\hline \multirow{6}{*}{ İşyerine nasil gidip geliyorsunuz? } & Aynı binada oturuyorum & 831 & 31.1 \\
\hline & Yürüyerek & 209 & 7.8 \\
\hline & Kendi Vasıtamla & 755 & 28.2 \\
\hline & Otobüs/Dolmuş & 806 & 30.1 \\
\hline & $\begin{array}{l}\text { Diğer (Otostop,Kurum } \\
\text { aracı,Karışık,Cevapsız) }\end{array}$ & 39 & 1.5 \\
\hline & Taksi/Servis & 36 & 1.3 \\
\hline \multirow{5}{*}{ İş yerine ne kadar sürede ulaşıyorsunuz? } & $0-15 \mathrm{dk}$ & 1327 & 49.6 \\
\hline & $15-30 \mathrm{dk}$ & 652 & 24.4 \\
\hline & $30 \mathrm{dk}-1$ saat & 445 & 16.6 \\
\hline & $1-1.5$ saat & 213 & 8.0 \\
\hline & 2 Saat ve üzeri & 39 & 1.5 \\
\hline
\end{tabular}

Ebelerin \%76.4'ünün ehliyeti var iken, bunun \%72.4'ü araç kullanabildiğini beyan etmiştir. KatıIımcıların sadece \%28.2'si kendi aracı ile işyerine gidip gelmektedir. Ebelerin \%30'u otobüs ve ya dolmuş ile işe gitmektedir.

Sağılık evinde çalışan ebelerin mesleğe ilişkin algıları Tablo 6'da gösterilmiştir. \%86,8'i mesleğini severek yaptığını belirtirken, sadece $\% 19.8$ 'i özlük haklarının yeterli olduğunu düşünüyordu. \%72.5'u çalışma saatlerinden memnunken, \%41.3'ü ebeliği yıpratıcı bir meslek olarak görüyordu. \%40.2'si mesleğinden yeterince doyum sağlarken, sadece \%17.3'ü ekonomik imkanlarının yeterli olduğunu düşünüyordu. Mesleki açıdan yetişmek için gerekli olanakların sağlandığını düşünenlerin oranı \%24'de kalıyordu. Atama/yer değiştirmelerin adaletli olduğunu düşünenlerin oranı \%25.3 iken kurum ile ilgili önemli konu ve kararlarda görüş ve bilgilerime başvurulduğunu düşünenlerin oranı \%29.1 idi.
Sakarya Tip Dergisi

2018;8(2):344-351

KURT ve Ark.

Sağılı Evi Ebelerinin Çalışma Koşulları ve

Memnuniyet Durumlarinin Araştriılması 


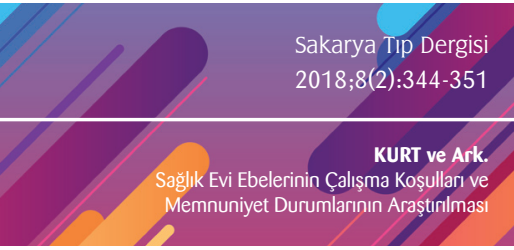

Tablo 6. Katılımcıların Mesleğe ilişkin Algıları

\begin{tabular}{|l|c|c|c|}
\hline & \multicolumn{3}{|c|}{ Yüzde Oranı } \\
\cline { 2 - 4 } & $\%$ Evet & \%Kısmen & \%Hayır \\
\hline Mesleğimi severek yapıyorum & 86,8 & 12,1 & 1,2 \\
\hline Özlük haklarımın yeterli olduğunu düşünüyorum & 19,8 & 45,6 & 34,6 \\
\hline Mesleğimin, kişilik özelliklerime uygun olduğunu düşünüyorum & 81,0 & 15,4 & 3,6 \\
\hline Mesleğimin çalışma saatlerinin uygun olduğunu düşünüyorum & 72,5 & 18,5 & 9,0 \\
\hline Yıpratıcı bir meslek olarak görüyorum & 41,3 & 42,2 & 16,5 \\
\hline Mesleğimden yeterince doyum sağlıyorum & 40,2 & 42,5 & 17,3 \\
\hline Mesleğimin ekonomik imkanlarının yeterli olduğunu düşünüyorum & 17,3 & 42,2 & 40,5 \\
\hline Hizmet içi eğitimlerin/seminerlerin sayıca yetersiz olduğunu düşünüyorum & 32,4 & 34,8 & 32,8 \\
\hline $\begin{array}{l}\text { Hizmet içi eğitimlerin/seminerlerin içerik yönünden zayıf olduğunu } \\
\text { düşünüyorum }\end{array}$ & 20,5 & 36,7 & 42,8 \\
\hline $\begin{array}{l}\text { Mesleki açıdan yetişmemiz için gerekli olanakların sağlandığını } \\
\text { düşünüyorum }\end{array}$ & 23,9 & 43,5 & 32,7 \\
\hline Zorunlu hizmetten dolayı yaşadığım yer değişikliği beni olumsuz etkiledi & 23,4 & 22,2 & 54,4 \\
\hline Kurum yönetimi ile ilgili iletişim ve iş birliği yönünden sorunlar yaşıyorum & 11,0 & 22,4 & 66,6 \\
\hline $\begin{array}{l}\text { Kurum ile ilgili önemli konu ve kararlarda görüş ve bilgilerime } \\
\text { başvurulduğunu düşünüyorum }\end{array}$ & 29,1 & 38,5 & 32,5 \\
\hline Meslektaşlarımız ile kurum içi ve dışı sorunlar yaşıyorum & 4,0 & 13,8 & 82,2 \\
\hline $\begin{array}{l}\text { Yaptığım işe toplumun, yeterince saygı duyduğunu ve değer verdiğini } \\
\text { düşünüyorum }\end{array}$ & 33,7 & 42,9 & 23,3 \\
\hline $\begin{array}{l}\text { Mesleğimin, toplumun gelişmesine önemli katkılarının olduğunu } \\
\text { düşünüyorum }\end{array}$ & 80,0 & 17,2 & 2,7 \\
\hline Mesleki anlamda gerekli sosyal-kültürel faaliyetlere katılıyorum & 34,5 & 41,3 & 24,2 \\
\hline
\end{tabular}

\section{Tartışma}

Ebelik mesleğinin statüsünün arzu edilen noktaya getirilebilmesi; hem hizmet kalitesini hem de bireysel başarıyı artıracağı için mesleği bilinçli olarak seçmesi, kişilik özelliklerine uygun olması ve mesleğini severek yapması gereklidir. Çalışmamıza katılanların \%87'si mesleğini severek yaptığını belirtiyor, \%81'i de mesleğinin, kişilik özelliklerine uygun olduğunu düşünüyordu. Konya'da üniversite hastanesinde yapılan çalışmada hemşirelerin \%50'si mesleğine karşı duygusal bağlılık hissettiğini, \%56'sı mesleğini yapmaktan memnun olduğunu ve \%69'u mesleğin kendilerine uygun olduğunu belirtmiştir. ${ }^{6}$ Sivas'ta kamu hastanelerinde yapılan çalışmada \%42'si mesleklerinde iş tatmini yaşamadıklarını belirtmişlerdir. ${ }^{7}$ Çalışmamızda ise bu oran \%17'dir. íkinci ve üçüncü basamağa göre birinci basamakta çalışanların mesleki sevgi ve tatmininin daha yüksek olduğu görülmektedir.

Çalışmamıza katılanların sadece \%34'ü yaptığı işe toplumun, yeterince sayg duyduğunu ve değer verdiğini düşünüyordu. Denizli’de öğrenim gören hemşirelik ve sağlık memurluğu öğrencileri arasında yapılan çalışmada katılımcıların sadece \%14'ü toplumun mesleğe bakışının olumlu olarak gördüğü bildirilmiştir. ${ }^{8}$ istanbul'da kamu hastanelerinde yapılan bir başka çalışmada mesleklerinin, toplumda en güvenilen meslekler arasında olduğunu düşünen ebelerin oranı \%13 olarak bulunmuştur. ${ }^{9}$ Ebe ve hemşirelerin toplumsal algısına ilişkin iyileştirilmeler yapılmalıdır.

Çalışmamızda özlük haklarının yeterli olduğunu düşünen katılımcı oranı \%20'de kalmıştı. Bunun esas nedenini ekonomik imkanların yetersiz olması oluşturmaktadır. Nitekim, çalışmamıza katılanların sadece \%17’si mesleğinin ekonomik imkanlarının yeterli olduğunu düşünüyordu. Denizli'de 
hastanelerde çalışan hemşirelerde yapılan bir çalışmada hemşirelerin sadece \%14'ü aldıkları ücreti yeterli görmüştür. ${ }^{10}$ Denizli'de sahada çalışan ebeler üzerinde yapılan bir araştırmada katılımcıların en düşük iş doyumunun ücret boyutunda olduğu bildirilmiştir. ${ }^{11}$ Ankara'da üniversite hastanelerinde çalışan hemşire ve ebelerde yapılan bir çalışmada da iş performansında en etkili faktörün, ücret olduğu bulunmuştur. ${ }^{12}$

Çalışmamıza katılan ebelerde kurum ile ilgili önemli konu ve kararlarda görüş ve bilgilerine başvurulduğunu düşünenlerin oranı \%29'da kalıyordu. isstanbul'da kamu hastanelerinde yapılan çalışmada da benzer bulgulara ulaşılmıştır.9 Ebelerin motivasyonlarını ve iş doyumlarını artırmak için kararlara katılma ve görüş alma süreçlerine katkıda bulunması sağlanmalıdır.

Sağlık sektöründeki hızlı değişime ayak uydurmak için mesleki eğitimler düzenlenmesinin önemi çok büyüktür. Çalışmamızda katılımcıların sadece \%24'ü mesleki açıdan yetişme için gerekli olanakların sağlandığını düşünüyordu. İstanbul'da kamu hastanelerinde yapılan çalışmada da benzer şekilde ebelerde bu oran \%16 olarak bulunmuş̧ur. ${ }^{9}$ Hizmet içi eğitimlerin yetersiz olması çalışanların verimliliğini de olumsuz etkilemektedir.

Sağlık evi binası kolay ulaşlabilir, güvenli, uygun havalandırma, ısıtma ve aydınlatma imkânlarına sahip olmalıdır. Sağlık evleri üst kat lojman olacak şekilde 2 katlı planlanmalıdır. Hizmet binası kısmı için yaklaşı $70 \mathrm{~m} 2$, lojman kısmı için de yaklaşık $60 \mathrm{~m} 2$ alan düşünülmelidir. Sağılık evi standartları için teknik özellikler aşağıdaki gibi belirlenmiştir: ${ }^{13}$

1. Kat: Hizmet Binası (Sağlık Evi) Kısmı: Giriş Holü, Ebe Çalışma ve Poliklinik Odası, Gebe İzlem ve Üreme Sağlığı Odası, Arşiv ve Depo alanı, Lavabo ve WC

2. Kat: Lojman Kısmı

Çalışmamızda sağılık evi binasının fiziksel durumunu yeterli veya çok yeterli görenlerin oranı \%22,1 idi. Sağlık evlerinin \%90'ında çalısma ve poliklinik odası bulunurken \%51'inde gebe izlem ve aile planlaması odası bulunmuyordu. Çalışma ve poliklinik odalarının \%41'inde gerekli demirbaş ve malzemeler tam değildi. Sağık evlerinin \% 75 'inde özürlü ve yaşlı hastaların giriş ve çıkışlarını mümkün kılan kolaylaştıııcı tedbirler alınmamıştı.

\section{Sonuç}

Sonuç olarak, sağlık evi ebelerinin mesleki memnuniyeti yüksek olmakla birlikte, özlük hakları konusunda bazı talepleri mevcuttur. Ayrıca, sağılk evlerinin fiziksel durumları konusunda da yetersizlikler mevcuttur. Bu durumların iyileştirilmesi sayesinde ebeler, sağıkı/hasta birey, ailesi, toplum ve sağlık ekibi üyeleri ile olumlu ilişkiler kurabilecek ve dolayısı ile hem sosyal hem iş yaşamlarında mutlu, üretken bireyler olarak verdikleri hizmetin kalitesi artacaktır. Bu çalışmanın sonuçlarının, birinci basamak politikaları geliştirme konusunda yararlı olabileceği düşünülmektedir.
Sakarya Tıp Dergisi

2018;8(2):344-351

KURT ve Ark.

Sağılk Evi Ebelerinin Çalışma Koşulları ve

Memnuniyet Durumlarının Araştırılması 
1. Sağlık Hizmetlerinin Sosyallestirilmesi Hakkında Kanun. https://www. saglik.gov.tr/TR,10388/sayisi224--rg-tarihi12011961--rg-sayisi10705-s aglik-hizmetlerinin-sosyallestirilmesi-hakkinda-kanun.html

2. Türkiye Halk Sağığı Kurumu Tașra Teșkilatı Hizmet Birimlerinin Görevleri, Çalışma Usul Ve Esasları ile Kadro Standartları Hakkında Yönerge. http:// www.thsk.gov.tr/dosya/mevzuat/yonergeler/THSK_tasra_yonerge si_guncel.pdf

3. Toplum Sağlığı Merkezi Ve Bağı Birimler Yönetmeliği. http://www.resmigazete.gov.tr/eskiler/2015/02/20150205-5.htm

Sakarya TIp Dergisi 2018;8(2):344-351

$$
\text { gisi, 2005; 68(1): 29-32 }
$$

5. Karahaliloğlu N. Cerrahi Kliniklerde Çalışan Hemşirelerde Tükenmişlik ve iş Doyumu Düzeylerinin İncelenmesi. Yüksek Lisans Tezi, Haliç Üniversitesi Sağlık Bilimleri Enstitüsü, İstanbul, 2013.

6. Demirkan E. Hemşirelerde Mesleki Motivasyon Eksikliğinin Nedenleri ve
8. Derya Beydağ K, Gündüz A, Gök Özer F. Sağllk yüksekokulu öğrencilerinin eğitimlerine ve mesleklerine bakış açıları, meslekten beklentileri. Pamukkale Tip Dergisi, 2008, 1: 3, 137-142.

9. Yılmaz FT, Sen HT, Demirkaya F. Hemsirelerin ve ebelerin mesleklerin algılama biçimleri ve gelecekten beklentileri. Sağık ve Hemşirelik Yönetimi Dergisi, 2014, 1.3: 130-139.

10. Barutçu E, Serinkan C. Günümüzün önemli sorunlarından biri olarak tükenmişlik sendromu ve Denizli'de yapılan bir araștırma. Ege Akademik Bakış, 2008, 8: 2, 541-561.

11. Oflaslı F. Denizli İlinde Sahada Çalışan Ebelerin iș Doyum Düzeylerinin Belirlenmesi. Yüksek Lisans Tezi, Pamukkale Üniversitesi Sağlık Bilimleri Enstitüsü, Denizli, 2002 Sonuçları Üzerine Sosyolojik Bir Çözümleme. Yüksek Lisans Tezi, Selçuk Üniversitesi Sosyal Bilimler Enstitüsü, Konya 2007.

7. Karakuș, H. Hemșirelerin iș tatmin düzeyleri: Sivas ili örneği. Dicle Üniversitesi Sosyal Bilimler Enstitüsü Dergisi, 2011, 3: 6, 46-57.
12. Korkmaz S. Hastanelerde Doktor, Hemşire ve Ebelerin Motivasyonunu Etkileyen Faktörler: Bir Uygulama. Yüksek Lisans Tezi, Çağ Üniversites Sosyal Bilimler Enstitüsü, Mersin, 2008.

13. TC Sağlık Bakanlığı Halk Sağlığı Kurumu Başkanlığı. Birinci Basamak SağIık Kurulușları Prototip Proje Ihtiyaç Listesi Rehberi, Ankara, 2012. 